This is the post print version of the article, which has been published in Communications in Computer and Information

Science 2018, 810, 683-692.

The final publication is available at Springer via

https://doi.org/10.1007/978-3-319-74334-9_70

\title{
Lower Secondary School Teachers' Experiences of Developing Inquiry-Based Approaches in Information Literacy Instruction
}

\author{
Tuulikki Alamettälä ${ }^{1}$ and Eero Sormunen ${ }^{1}$ \\ ${ }^{1}$ University of Tampere, Faculty of Communication Sciences, Tampere, Finland \\ \{tuulikki.alamettala, eero.sormunen\}@uta.fi
}

\begin{abstract}
Inquiry-based assignments are commonly used in information literacy (IL) instruction. However, guiding pupils through the inquiry process is challenging as the school's traditional instruction practices are teacher-centered. Yet, there are teachers who continuously develop their personal pedagogies in IL instruction, but we have very little research insight into that. This paper reports on a two-year longitudinal case study based in the classrooms of a lower secondary school teacher. The teacher and her two colleagues were engaged in enhancing their pedagogical practices in IL instruction. The findings based on interviews and classroom observations indicate that the teachers use various types of assignments and instructional activities for IL instruction.
\end{abstract}

Keywords: Information literacy instruction, teachers, lower secondary schools.

\section{Introduction}

Previous research into information literacy pedagogies indicates that IL receives minimal specific attention in teacher education [1]. Studies among practicing teachers suggest that IL instruction is often weakly designed, concentrates mainly on technical aspects and leaves the crucial stages of the learning process without adequate attention [2]. Although the overall picture of the current situation in schools is overshadowed, there are teachers who continuously develop their instructional practice in IL [3].

Pedagogical models for IL instruction have been developed within library and information science. Guided Inquiry might be one of the most established, researchbased frameworks [4]. There is also a body of literature introducing related instructional designs from the viewpoint of teachers' professional development [5]. The problem is that these models have not been integrated into national development projects and are not widely applied in schools.

In this paper, we focus on the micro level: what happens in classrooms where a lower secondary school teacher develops her professional practice in IL instruction. We adopted a longitudinal approach enabling us to study IL instruction in various curricular situations during a two-year period. The aim of the study is to create a better understanding of teachers' IL instruction practices and their ways of developing their methods in IL instruction. 


\section{The Framework of the Study}

Most scholars in education acknowledge that teacher-directed instruction as well as the sole use of textbooks and workbooks are no longer meaningful pedagogical practices [6]. Inquiry-based learning is a well-known learner-centered pedagogical approach that actively involves students in their own learning. Inquiry-based learning requires the learner to observe, ask questions, discover gaps in their own knowledge base and study resources to bridge these gaps [7].

The need to improve students' information literacy is closely connected to the progress towards learner-centered pedagogies. Inquiry-based assignments, such as essays, are commonly used in IL instruction since they require independent acquisition and use of information sources. However, adoption of new pedagogical practices is still a challenge for teachers as they have to guide students to work independently in information environments that teachers cannot fully control [4].

\subsection{Guided Inquiry}

Guided Inquiry (GI) [4] is grounded in Kuhlthau's extensive studies of the Information Search Process (ISP) model [9]. GI is built around the ISP with specific direction for guiding students in each phase of the inquiry process. It is based on the idea that information literacies are best learned by training appropriate information practices in a genuine collaborative process of inquiry.

GI divides the inquiry process into eight phases: 1) open, 2) immerse, 3) explore, 4) identify, 5) gather, 6) create, 7) share, and 8) evaluate. The teacher steers the process with instructive interventions, offering targeted support for the specific phases of the process. GI emphasizes the phases before collecting information (i.e., phase 5). Students are prepared for information gathering by arousing their curiosity, sharing what is already known, building up background knowledge, and exploring ideas. [4]

Students are guided to enhance their learning by using three inquiry tools. Inquiry journals help reflect on personal learning. Inquiry logs help keep track of important information sources. Inquiry charts help visualize ideas about the topic being studied. GI applies two types of collaborative forum. The whole class (inquiry community) is used to introduce and motivate the assignment and share results. Small groups (inquiry circles) are the main forum for learning activities.

GI recommends that teachers and librarians with varied expertise are organized to create flexible teams. Teams plan and supervise the inquiry. The school librarian is a specialist on information resources. Teachers work as curriculum content experts. [4]

\subsection{Pedagogical Practices in Finnish Schools}

It has been argued that teachers in Finland have good opportunities for professional development. Teacher education is research-based and offers teachers knowledge and methods to develop teaching and to solve pedagogical problems [10]. It has been argued 
that the curricular framework supports the change of practices. However, the mainstream form of instruction has appeared to be quite conservative using traditional instructional methods with textbooks [11].

The Finnish national core curriculum presents the objectives and core contents of all school subjects, and describes the mission, values, and structure of education. Municipalities, schools and teachers themselves draw up their own local curricula within the national framework [12]. This approach provides teachers with an opportunity to take their own classroom context into account.

The national core curriculum for basic education emphasizes the learning goals in multiliteracies. Multiliteracies are defined as being competences associated with acquiring, interpreting, producing and evaluating a variety of texts. By definition, multiliteracies strongly overlap with information literacy. Multiliteracies should be developed in all teaching and learning, integrated into all school subjects [12].

\section{$3 \quad$ Research Setting}

This paper reports on a two-year case study in the classrooms of a lower secondary school teacher and her two colleagues who were engaged in enhancing their pedagogical practices in IL instruction. Guided Inquiry was introduced to the teachers but they were free to apply it as they saw fit. The aim was to create a better understanding of the pedagogical challenges that teachers face when they apply inquirybased approaches as an everyday school practice. The research questions of the study were:

1. What kind of pedagogical designs do teachers develop for inquiry-based information literacy instruction?

2. To what extent were the observed pedagogical designs similar to the designs of Guided Inquiry?

3. How do teachers experience their possibilities and success in developing inquirybased information literacy instruction in their everyday school context?

\subsection{School Context}

Compulsory education in Finland consists of a nine-year comprehensive school system, from the age of 7 to 16 . The first 6 years are spent at primary school under the leadership of a classroom teacher. For the last 3 years, pupils move to lower secondary school where classes are taught by a variety of subject teachers.

This study followed the work of a Finnish language and literature teacher for two years from the 7th to the 8th grade. The lower secondary school studied also serves as a teacher training school in Southern Finland and has approximately 300 students. The school is a part of, and works in close collaboration with, the local university. It functions as an environment for development, experimentation and research for its own employees and university researchers. It can be argued that the school represents the current state of the art in research-based pedagogies. 


\subsection{Participants and Modules Studied}

Data were collected during the 2015-2016 and 2016-2017 school years. The Finnish language and literature teacher (the Teacher for short) taught three parallel classes (1920 pupils per class). She had six courses with them during the study period. We collected data during the first, third and fourth courses. The courses were chosen as it was easy to see that their learning goals were explicitly associated with IL themes. Two history teachers were also involved since the Teacher organized the third course in close collaboration with a history course. One of the history teachers taught two of the classes, and the other took one class.

The Teacher has a Master's degree and subject teacher education in Finnish language and literature. She has 11 years of work experience in teaching. She has supervised student trainees for five years. The history teachers were experienced teachers with similar work roles.

The Teacher planned and implemented three modules for information literacy instruction. Modules 1 and 3 were part of Finnish language and literature courses (Finnish language for short). Module 2 was integrated into a joint project of Finnish language and history. In module 1 (Sep 2015), pupils made a brochure about social media. In module 2 with history (Apr-May 2016) pupils gave a presentation and wrote a fictive text about the Finnish Civil War. In module 3 (Sep-Nov 2016), each pupil prepared and presented an argumentative speech.

\subsection{Data Collection and Analysis}

Data were collected through thematic interviews, which are designed to provide insight into what participants know and think about the research question [see e.g. 13]. The first author interviewed the Teacher for the first time at the beginning of her first course in August 2015 and for the final time after the fourth course in April 2017. The themes of the pre-interview were built on the Teacher's earlier experiences regarding IL instruction: what kind of problems she had faced, what kind of development needs had arisen and which Guided Inquiry activities she found useful. In the last interview, the Teacher was asked about her experiences of the whole two-year period: what new things she had experienced, how implementation had succeeded and how she felt that the pupils or the Teacher had benefitted from the projects. The pre-interview lasted 30 minutes and the post-interview 15 minutes.

Additionally, the Teacher was interviewed before and after each module. The preinterviews dealt with the learning goals and the practicalities of the courses. Experiences of the modules were surveyed with post-interviews. The history teachers were interviewed regarding the second module too. The interviews lasted from 15 to 35 minutes. The Teacher was interviewed separately, the history teachers together.

In order to get an overall picture of what was happening in the classrooms, the first author observed all the relevant project lessons (3-4 lessons per class during the first module, 8-10 lessons per class during the second module, 3-5 lessons per class during the third module) and wrote memos. Lessons lasted 45 - 75 minutes. The memos and 
all the material that was handed out during the lessons were used as a support material for analysing the interview data.

Data were exposed to content analysis. The analysis was divided into two parts; descriptive and analytical. In the descriptive part, data were analyzed based on the research questions and taking the research setting into account. In the analytical part, data were exposed to deductive, theory-guided, content analysis. In the deductive content analysis, the themes are drawn from existing theoretical ideas that the researcher brings to the data [14] - in this case from Guided Inquiry [4].

The transcribed interviews were hand-coded directly into the text documents. The interviews were reviewed with attention paid to the research questions for themes. The observation memos and the handouts were used to support the analysis. Lastly, the themes were interpreted using Guided Inquiry as an analytical framework.

\section{$4 \quad$ Results}

The results of data analyses are presented one module at time. Firstly, the themes and goals of the module are introduced. Next, the applied design patterns are presented $\left(1^{\text {st }}\right.$ descriptive part), and compared with the designs of the Guided Inquiry (analytical part). Finally, teachers' experiences are described ( $2^{\text {nd }}$ descriptive part).

\subsection{Module 1}

The first module was carried out with the 7th graders during the Fall term of their first year at lower secondary school. The pupils created a brochure about social media for 5th graders emphasizing how to use it appropriately. The Teacher said that the main learning goal was for the pupils to learn to seek information and to apply it in writing for a target audience. Netiquette was the learning goal in the subject content.

Design. The Teacher defined the target audience so that the pupils had to think about how to transform the text from the sources into their own text in order to write clearly enough for younger children. The work was done in pairs so that the pupils would learn to cooperate and to share their knowledge. Group discussions at the beginning of the project aimed to activate interaction and collaboration between pupils. The pupils were guided to use inquiry logs for keeping track of information sources.

Guided Inquiry. The Teacher borrowed the idea of inquiry logs from GI. As recommended in GI, she chose a project theme that she felt was familiar to the pupils and she let the pupils choose their subtopics. The thinking here was to engage pupils in their work. GI also emphasizes that pupils should be prepared to seek information by stimulating their curiosity and interests, and sharing what is already known. The Teacher aimed to achieve this by letting pupils discuss the theme, firstly in inquiry circles and then working together in an inquiry community. 
Experiences. The Teacher reported that most pupils seemed to enjoy the project. She thought that the pupils had learned about seeking and using information, as well as about working in pairs. However, the Teacher saw huge differences in how well pupils sought and then used information. The Teacher reported that a common problem was that many inquiry logs were not filled in completely and some others were lost. Most of the pupils finished the project in a hurry. Incomplete bibliographies were one indicator of this hurry. The use of information sources was somewhat problematic. The Teacher saw copying and pasting from Wikipedia. Some pupils used low quality websites as their sources.

All things considered, the Teacher thought that the assignment was probably too complicated. Several things were calling for the pupils' attention at the same time. The Teacher concluded that simpler assignments would be more useful. She suggested that a more concrete example of the end product should have been shown to the pupils. The observations confirmed that the pupils seemed to wait for specific instructions on what and how they should do. The Teacher was not satisfied with the inactive use of inquiry logs (on paper). She argued that an electronic log might have been more effective.

\subsection{Module 2}

The Teacher cooperated with two history teachers for the second module. It was carried out during the Spring term. In the history course, pupils gave a presentation about the Finnish Civil War. In the Finnish course, the pupils wrote a fictive text which they based on facts learned during the history lessons. The teacher team hoped that pupils would learn to seek and use diverse information sources and to present justified opinions. The Teacher wanted the pupils to learn that seeking information contributes to fictive writing and is a part of it. Learning criticism of sources was set as an important goal by the history teachers. From the pedagogical point of view, the Teacher expected joint teaching units to give more time to the first phases of inquiry and the pupils could then concentrate more thoroughly on the theme.

Design. Pupils' orientation to the theme was emphasized in the design of the unit. The pupils paid a visit to a museum to see an exhibition of the Finnish Civil War before the project started. The visit was expected to perform as a cognitive and emotional trigger encouraging the pupils to think about the theme and inspire them in their work.

The teacher team wanted pupils to learn to manage their sources more systematically and continued to guide them in the use of inquiry logs. The logs were in electronic format. In order to offer diverse information sources to the pupils, the history teachers brought books from their own collections and also gave the pupils tips about useful internet sites. The assignments were done individually for both subjects, but some activities were also done in inquiry circles. In history, the pupils had group discussions about their themes and about how to outline the topics. In Finnish, the pupils gave written feedback to their classmates in the middle of the writing process as well as afterwards. In history, the pupils got feedback from the others at the end. 
Guided Inquiry. Some pedagogical designs used in the module were similar to GI. The pupils' curiosity was stimulated by a museum visit, the pupils were free to choose their topics within the main theme, and inquiry logs were used. The pupils wrote their own texts individually but worked at some point in inquiry circles. More time and attention was devoted to the first phases of the inquiry process: open, immerse, explore. The three teachers formed a learning team - as emphasized in GI. GI also encourages the team to offer the pupils a variety of sources as the history teachers did.

Experiences. The Teacher noted that the work done in history influenced the pupils' activities in her class. The pupils chose topics that they knew about and got ideas from the history class. The Teacher felt that the pupils made progress in process writing. The fictional writing process did not require much information seeking as the pupils used information that they had already found for their history work. However, the Teacher saw that some learned about acquiring information for writing fiction.

According to the history teachers, the pupils were positive about the assignment and seemed to find and choose topics of their own interest. The museum visit motivated pupils for the learning task. The history teachers felt that even those who were not initially interested in history showed some signs of engagement. They also argued that pupils paid more attention to the language of their presentations than they usually do. The history teachers reported that pupils learned about subject content, information seeking and evaluation. The pupils who had used the inquiry log managed to synthesize information across sources better than those who had not used it. The history teachers experienced that most pupils' problems dealt with finding and analyzing information. They did not use eagerly the sources offered by the teachers.

The teacher team also noticed that some pupils had difficulties getting started and choosing the topic and some changed their topic if they did not find information at once. Copying and pasting caused a minor problem. Although the inquiry logs were in electronic format this time, they were not actively used.

All of the teachers were quite satisfied with the second assignment apart from the fact that there was too little time for shared activities between subjects at the end. They suggested that a shared launch of the module would have been useful, too. The Teacher expressed that organizing the project in one class at a time instead of in parallel in three classes would be one way to enhance collaboration.

\subsection{Module 3}

The third module was again a one-subject course in Finnish language and it was carried out in the Fall term of the second school year with pupils who were now 8th graders. Each pupil gave a five-minute speech about a theme of their choice. The aim was to convince the audience of one's message, and to learn to justify one's opinions. The Teacher's aim was that the pupils recognize what they already know about the subject matter and to analyze what kind of further information they need. The Teacher emphasized that seeking information was not the main issue but that it would help to complete the task. The pupils needed information to justify their opinions. 
Design. Before handing out the assignment, the Teacher asked pupils to think about what could be improved at their own school, in their hometown and in Finland. She wrote some of the pupils' answers on the blackboard and then explained the assignment. She emphasized that pupils need to seek information in order to justify their message. She prepared worksheets for the pupils to write down what they know about the subject in advance. In addition, pupils were asked to plan what kind of further information they would need and where to find it. Inquiry logs were again used in printed form.

Guided Inquiry. Pupils' own choice, inquiry logs and emphasis of the first phases of inquiry associated the designs with GI. The Teacher wanted pupils to concentrate especially on what they already know and thus emphasized the immerse phase of GI.

Experiences. According to the Teacher, the third module went as planned. Most pupils managed to perform at their own level. They learned about giving a speech but only a few had searched for information for their speeches. The observations revealed that some pupils pondered their topic selection for a very long time. Some thought that they did not need any information or could not search for it. Not all filled in the worksheet. Again, the inquiry logs were incomplete. The Teacher reported that pupils had problems when choosing a topic for their speech, when seeking information and when justifying their opinions. Some pupils had not prepared their speeches at all.

The Teacher felt that she should have emphasized more the importance of seeking information and provided more personal guidance for pupils. She argued that the pupils failed to see seeking information as a learning goal. She suspected that there were too much content in the worksheets. She thought that it might have been better to seek information separately, before pupils began planning the speech. On the other hand, she hesitated to make seeking information a separate part of the process.

\section{$5 \quad$ Discussion and Conclusions}

The current study explored how inquiry-oriented teachers develop information literacy instruction as part of their everyday school practices. The practices of information literacy instruction are typically studied in the context of a single teaching unit. We adopted a wider perspective by monitoring how the Teacher taught her three classes during two school years. Data were collected by taking a sample of three assignments, each from a different course. The advantage of this approach is that we could study pedagogical practices in varying curricular contexts. However, all three assignments were part of the same curricular track both for the Teacher and for pupils. We may think that this increases the validity of our data since varying modules and courses shed light on the Teacher's pedagogical ideas and practices from varying angles.

Findings. The results show that the teachers are ready to apply diverse assignments in IL instruction. The teachers implemented four assignments. None of them was a 
traditional essay. The formats were a brochure, a presentation, a fictive text and a speech. Diverse assignments lead to diverse inquiry processes, activities and guidance.

Guided Inquiry emphasizes similar issues as the Finnish curriculum. Thus, the teachers were partly familiar with them. They devoted attention to the first phases of the inquiry process (open, immerse, explore, identify) and introduced various designs for how to do this. They also gave more space for pupils to choose topics that interested them. Inquiry logs were introduced to the pupils. The pupils worked in different groups and the teachers also worked partly as a team. But, apart from Guided Inquiry, the librarian was not involved. In Finland, different professions tend to be quite territorial and cooperation is not always self-evident.

The teachers experienced that investment of their time in the first phases of inquiry paid off: the pupils seemed to find topics that interested them. They also seemed to gain from cooperation between the two subjects. The teachers saw that pupils who used inquiry logs managed to synthesize information across sources more effectively than those who did not use them. Choosing the topic, finding and analyzing information was difficult for some pupils. Sometimes it was difficult to strike a balance between phases. For example, emphasizing the pupils' own knowledge (immerse) could lead to passivity when seeking information (explore, identify, gather). Technical problems and a lack of IT-skills occasionally steered pupils' attention towards technical issues instead of working on information and writing.

It seemed that not all pupils are attuned to working in a learner-centered way and are waiting for clear instructions. This may affect motivation and cause indifference to the assignments which was evident with some pupils. But, all in all, the teachers felt that inquiry-based learning is a fruitful approach and that the meaning of information seeking is something that should be emphasized to the pupils.

Future research. The work reported here is part of a broader study. We also collected survey data in the classroom of pupils' online inquiry attitudes, self-efficacy and practices. In addition, the pupils completed online tests which measured their skills in searching the web and evaluation of sources. The surveys and competence tests were carried out at the beginning, in the middle and at the end of the research period both in the three classes taught by the Teacher and in two control classes at the same school. Thus, we can analyse the long-term changes in various variables among the pupil population and compare them with the Teacher's experiences.

Limitations of the study. The case study focused on one teacher and her two colleagues at a teacher training school. Subsequently, the results cannot be generalized to Finnish lower secondary schools or other schools. However, we may expect that the ecological validity is good since the teachers were planning and implementing their pedagogical ideas as part of their regular work in the framework of the national and local curriculum.

Conclusions. Our concluding remarks are the following: We have introduced a novel approach for case studies on the practices of IL instruction in schools. Our longitudinal approach enables teachers to concentrate on development of the instruction across a 
long period of time. For the researcher, it helps to dig deeper into teachers' pedagogical practices by exploring IL instruction in varying curricular contexts. The empirical findings suggest that teachers use various types of assignments and instructional activities for IL instruction.

Acknowledgements. The study was funded by the Faculty of Communication Sciences at the University of Tampere, Finland. The authors thank the teachers participating in the study. We also thank our colleagues at the TRIM research center for their constructive comments on the early version of the manuscript.

\section{References}

1. Tanni, M.: Teacher trainees' information seeking behaviour and their conceptions of information literacy instruction. University of Tampere, Tampere (2013)

2. Limberg, L., Alexandersson, M., Lantz-Andersson, A., Folkesson, L. What matters? Shaping meaningful learning through teaching information literacy. Libri, 58(2), 82-91. (2008)

3. Sormunen, E., Alamettälä, T.: Guiding Students in Collaborative Writing of Wikipedia Articles - How to Get Beyond the Black Box Practice in Information Literacy Instruction. In: Viteli, J., Leikomaa, M. (eds.) Proceedings of EdMedia 2014 - World Conference on Educational Multimedia, Hypermedia and Telecommunications, 2014(1), 2122-2130. (2014)

4. Kuhlthau, C. C., Maniotes, L. K., Caspari, A. K.: Guided Inquiry. Learning in the 21st Century (2nd ed.). Libraries Unlimited, Santa Barbara (2015)

5. Kiili, C., Mäkinen, M., Coiro, J. L.: Rethinking academic literacies; Designing multifaceted literacy experiences for pre-service teachers. Journal of Adolescent \& Adult Literacy, 57(3), 223-232. (2013)

6. Selander S., Kress, G.: Design för lärande - ett multimodalt perspektiv. Norstedt, Stockholm (2010)

7. Hmelo-Silver, C. E., Chinn, C. A., Chan, C. K., O’Donnell, A. M.: International handbook of collaborative learning. Routledge, New York (2013)

8. Chu, S.K.W., Tse, S.K., Chow, K.: Using collaborative teaching and inquiry project-based learning to help primary school students develop information literacy and information skills. Library \& Information Science Research, 33(2), 132-143. (2011)

9. Kuhlthau, C.C.: Seeking meaning: a process approach to library and information services (2nd. ed.). Libraries Unlimited, Westport (2004)

10. Jyrhämä, R., Maaranen, K.: Research Orientation in a Teacher's Work. In: Niemi, H., Toom, A., Kallioniemi, A. (eds) Miracle of education: The Principles and Practices of Teaching and Learning in Finnish Schools, 97-111. Sense Publishers, Rotterdam (2012)

11. Korkeamäki, R.-L., Dreher, M. J.: Early literacy practices and the Finnish national core curriculum. Journal of Curriculum Studies, 43(1). Routledge, New York (2011)

12. Finnish National Board of Education. Perusopetuksen opetussuunnitelman perusteet 2014. (National Core Curriculum of Basic Education.) http://WwW.oph.fi/download/ 163777_perusopetuksen_opetussuunnitelman_perusteet_2014.pdf

13. Cohen, L., Manion, L., Morrison, K.: Research Methods in Education. Routledge, New York (2000)

14. Mayring, P,: Qualitative Content Analysis. Forum Qualitative Sozialforschung / Forum: Qualitative Social Research, 1(2). (2000) 